\title{
CRIME MANAGEMENT SYSTEM - A REVIEW
}

Siddharth Sharma
Department of IT

ABESIT, Ghaziabad, U.P, India
Prachi Chauhan

Department of IT

ABESIT, Ghaziabad, U.P, India

\author{
Deepti Singh \\ Department of IT \\ ABESIT, Ghaziabad, U.P, India
}

\begin{abstract}
The "Crime Management System" may be a web-based website for online complaining and computerized management of crime records. Here during this website an individual who wishes to file a complaint or report an event must register before $\log$ in and once the admin authenticates the user, he or she will login into the web site and file a complaint. This complaint will be received by police and police can send a message regarding status of the complaint to the user who filed the complaint. Police can use this software to manage different crimes and a few of the works which is completed in police headquarters manually. Police gets their login password from admin directly. Some of the modules like news, safety tips, missing persons and most wanted criminals can be viewed through the website without logging in. So, this website helps police to seek out the issues within the society without them actually coming to the police headquarters.
\end{abstract}

Keywords - Introduction, Proposed Algorithm, System Design, Technology Description, Advantages

\section{INTRODUCTION}

1.1 The crime management system can help in storing the records associated with the criminals, cases, complaint record, history then on. this will allow an individual to enter or delete the records if necessary. of these records are often maintained during a single database. Security is maintained so on make sure that only the authorized users will have access to the system. This application is going to be one among the useful projects that the police can believe. This website can help in getting the knowledge of the criminals of the many years back. It also can help in minimizing most of the work of the police. The features which will be included during this website are as follows: Criminal record: This website can contain the details related to the criminals in the particular case.

1.2 Complaint registration: The details of the complaints that are registered can also be stored through this website.

1.3 Police database management: The details of the police in the particular police station can be maintained through this website.
The rest of the paper is organized as follows. Proposed embedding and extraction algorithms are explained in section II. System Design are presented in section III. Technology Description are presented in section IV. Concluding remarks are given in section VIII.

\section{PROPOSED AlgORITHM}

\subsection{MODULES}

2.1.1 Station module:

- Each of the station must first register with the website.

- Once the prospective station registers with the website they can avail the existing records.

\subsubsection{Citizen module:}

- Each of the citizens, who has a complaint to register, must first register on the Website.

- Once the registration is complete, the citizen can sign-in to the website $\&$ register their complaint.

2.1.3 Crime module: This module is used for entering all details about the crime.

2.1.4 Administrators Module: The module will be focusing on the maintenance like Master Data Maintenance, Removal of old and outdated data from the software etc.

\subsection{ACTORS OF THE PROJECT}

User: Posting the complaints, Posting the reminders and View the status of his complaint.

Administrator: Viewing the complaints, viewing reminders, Generating the reports.

Department: Detect the criminals and punish them according to the police laws. 


\section{SYSTEM DESIGN}

\subsection{System Flow Diagram}

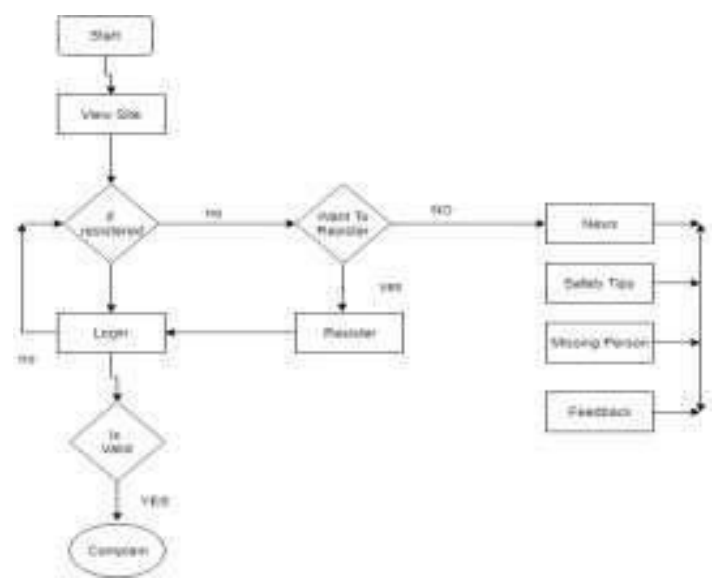

Fig 3.1 System Flow Diagram of CMS

\subsection{Use Case Diagrams}

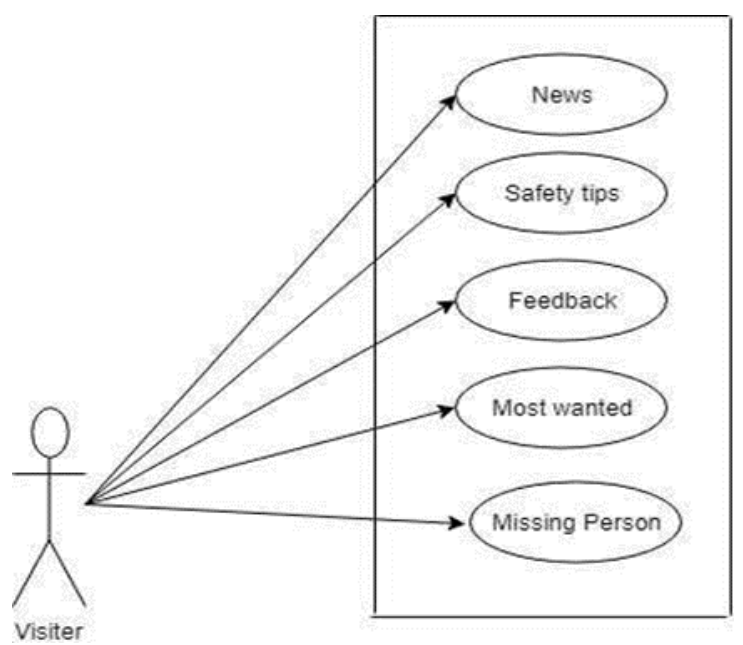

Fig 3.2. Visitor use case Diagram

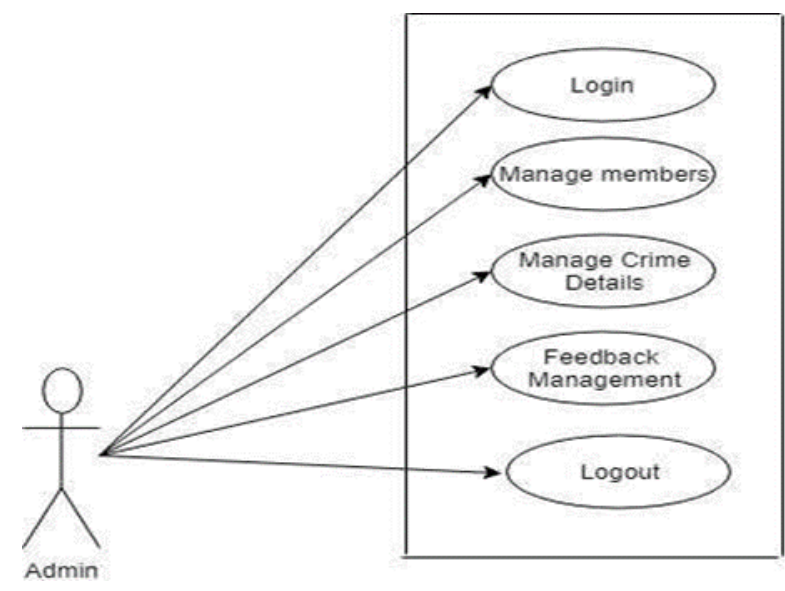

Fig 3.3 Admin use case Diagram

\section{TECHNOLOGY DESCRIPTION}

\subsection{HTML:3.2}

HTML stands for Hyper Text Mark-up Language, which is most widely used language on web to develop web pages. HTML refers to the way in which Web pages (HTML documents) are linked together. Thus, the link available on a web page is called Hypertext.

\subsection{CSS:}

CSS is meant primarily to enable the separation of document content from document presentation, including aspects like the layout, colours, and fonts. This separation can improve content accessibility, provide more flexibility and control within the specification of presentation characteristics, enable multiple HTML pages to share formatting by specifying the relevant CSS in a separate .css file, and reduce complexity and repetition within the structural content.

\subsection{MySQL:}

MySQL is an open source RDBMS that relies on SQL for processing the data in database. MySQL provides APIs for the languages like C, C++, JAVA, PHP and Python. MySQL is most commonly used for web applications and for embedded applications and has become a popular alternative to proprietary database system because of its speed and reliability. MySQL can run on UNIX, Windows and Mac OS. 


\section{International Journal of Engineering Applied Sciences and Technology, 2020 \\ Vol. 4, Issue 12, ISSN No. 2455-2143, Pages 554-557 \\ Published Online April 2020 in IJEAST (http://www.ijeast.com)}

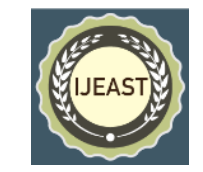

\subsection{PHP}

The PHP Hypertext Pre-processor (PHP) is a programming language that allows web developers to create dynamic content that interacts with databases.

- PHP is a recursive acronym for "PHP: Hypertext Preprocessor".

- PHP is a server-side scripting language that is embedded in HTML. It is used to manage dynamic content, databases, session tracking, even build entire commerce sites.

- It is integrated with a number of popular databases, including MySQL, Oracle, and Microsoft SQL Server.

- PHP is pleasingly zippy in its execution, especially when compiled as an Apache module on the Unix side. The MySQL server, once started, executes even very complex queries with huge result sets in record-setting time.

\subsection{JavaScript}

JavaScript is a light weight, interpreted programming language. It is designed for creating network-centric applications. It is complimentary to and integrated with Java. JavaScript is extremely easy to implement because it's integrated with HTML. It is open and cross-platform. 0

\section{Snapshots}

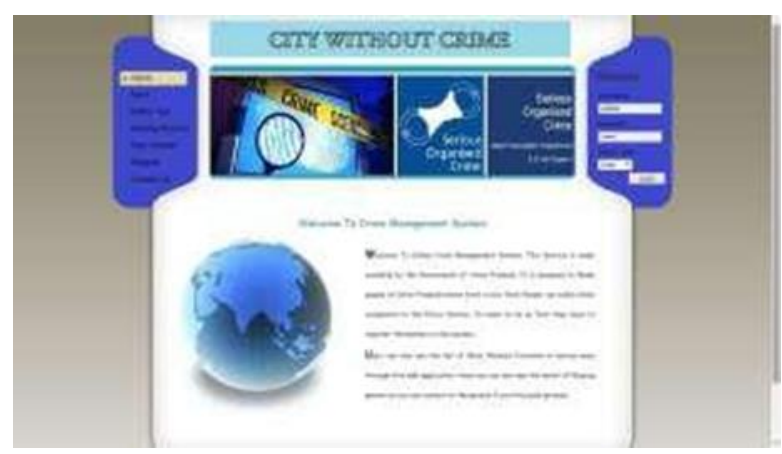

Fig 5.1. Page Name: Login Page

It shows the flow of login activity, where user, police and admin can able to login within the crime system along with valid/ registered username and password credential.

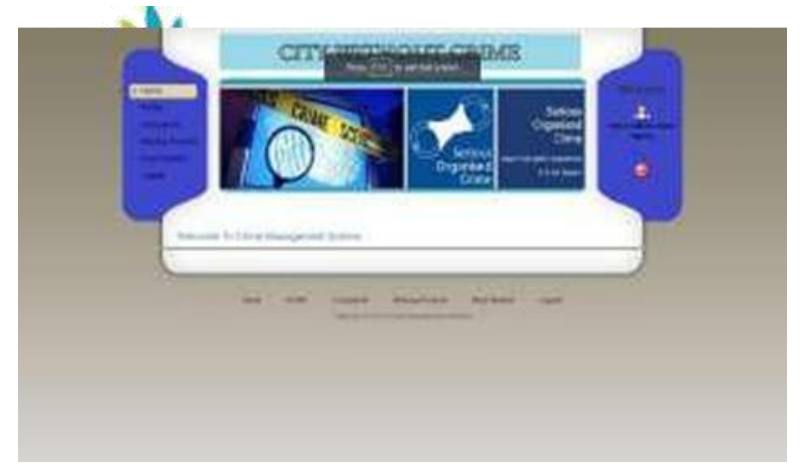

Fig 5.2 Page Name: Police Station Page

As login with Policemen credential, police can securely access all the activities like tracking complaints, information regarding missing person or most wanted person.

Also, securely able to update all the data across the alternate pages on the crime report system.

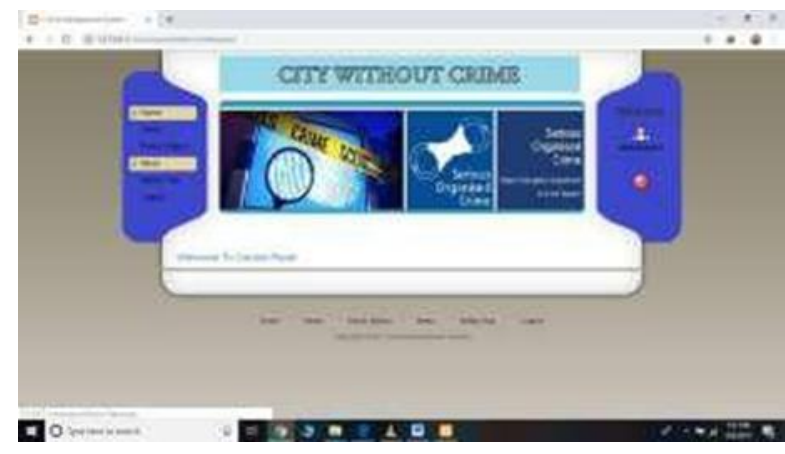

Fig 5.3 Page Name: Admin Page

As Admin login with its credential, Admin can able to access and maintain all the data across the police station, crime, most wanted, missing person and complaints pages.

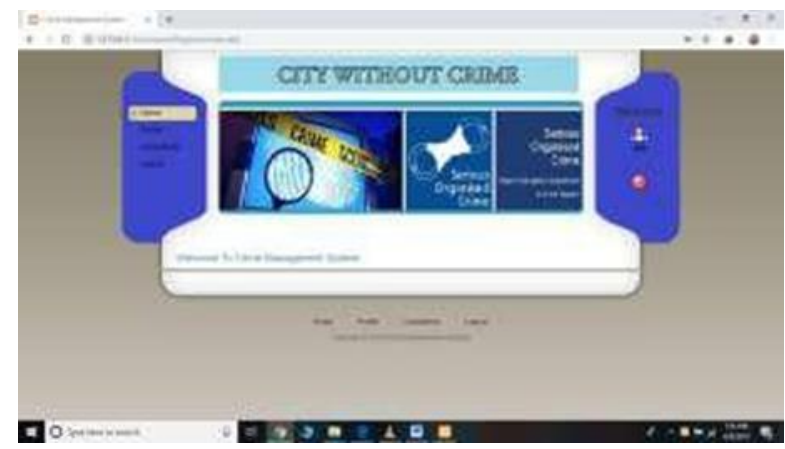

Fig 5.4 Page Name: User Page 


\section{International Journal of Engineering Applied Sciences and Technology, 2020 \\ Vol. 4, Issue 12, ISSN No. 2455-2143, Pages 554-557 \\ Published Online April 2020 in IJEAST (http://www.ijeast.com)}

User can able to access some pages like news, safety, missing person and most wanted without login as well. User should register itself if visiting first time and also able to login through which user can able to register complain, provide information regarding missing persons and most wanted, etc. Also, able to access all the pages.

\section{ADVANTAGES}

- Reduced time consumption

- No paper work needed

- No loss of records

- Centralized database management

\section{FUTURESCOPE}

The scope of the project includes that what all future enhancement scan be done in this system to make it more feasible to us:

- Databases for different products range and storage can be provided.

- Multilingual support can be provided so that it can be understandable by the person of any language.

- More graphics can be added to make it more user friendly and understandable.

- Manage \& backup versions of documents online.

\section{CONCLUSION}

Now- a-days everything is getting computerized. Manual work usually consumes tons of your time and is error prone. To make complaining easy and manage crime records this application is extremely helpful. Thus, Crime Management System overcomes most of the restrictions of the prevailing system alongside being very user-friendly application.

\section{REFERENCES}

[1] Steven Holzner, "HTML Black Book", Jon Skeet," C\# in depth.

[2] Skogan (1984), "Reporting crimes to the police: The status of world research", Journal of Research in Crime and Delinquency, vol. 21, pp. 113-37.

[3] Wikipedia-SQL Server Express https://en.wikipedia.org/wiki/SQL_Server_Express.

[4] Anil Jaiswal, Neeta Gunjal, Pooja Londhe, Shikha Singh, Ramesh Solanki, (2013) "Crime Automation \& Reporting System", International Journal of Science and Modern Engineering (IJISME), Volume-1, Issue
[5] .https://docs.microsoft.com/en-us/sql/sqlserver/?redirectedfrom=MSDN\&view=sql-server-ver 15 [6] Thorsten Sellin, "The Significance of Records of Crimes" The Law Quarterly Review, P. 489.

[7] Sachin Bagga, Akshay Girdhar, Munesh Chandra Trivedi and Yingzhi Yang, (2016) RMI Approach to Cluster Based Cache Oblivious Peano Curves, Second International Conference on Computational Intelligence \& Communication Technology.

[8] Harmanpreet Kaur, SachinBagga, Ankit Arora, (2015) RMI Approach to Cluster Based Winograd's Variant of Strassen's Method, IEEE 3rd International Conference on MOOCs, Innovation and Technology in Education (MITE).

[9] Ala' Alkhaldi, Indranil Gupta, Vaijayanth Raghavan, Mainak Ghosh, (2015) Leveraging Metadata in NoSQL Storage Systems.

[10] Shiju Sathyadevan, Crime analysis and prediction, IEEE, 25 Sept 2014,10.1109/CNSC.20 14.6906719 and Applications, vol. 25(2), pp. 443458.

[11] Zender (2003) 'Too Much Security?', International Journal of the Sociology of Law, 31 (3): 155-184.

[12] Ian Sommerville, "Software Engineering", Seventh Edition, Pearson Education, Inc., USA,2008, pp.43-63.

[13] Toshinobu Yasuhira, (2009) "Fundamental Upgrade of the Internal Network System within the National Police Agency of Japan", 43rd Annual 2009 International Carnahan Conference on Security Technology, 2009. pp.100-106 